Article

\title{
Four-State Coupled-Line Resonator for Chipless RFID Tags Application
}

\author{
Wazie M. Abdulkawi *(D) and Abdel-Fattah A. Sheta \\ Department of Electrical Engineering, King Saud University, Riyadh 11421, Saudi Arabia; asheta@ksu.edu.sa \\ * Correspondence: walkadri@ksu.edu.sa; Tel.: +966-11-46-76796
}

Received: 29 April 2019; Accepted: 23 May 2019; Published: 25 May 2019

check for updates

\begin{abstract}
A novel quad-state coupled-line microstrip resonator is proposed for compact chipless radio frequency identification (RFID) tags. The proposed resonator can be reconfigured to present one of four possible states: $00,01,10$, and 11 , representing, no resonance, resonance at $f_{2}$, resonance at $f_{1}$, and resonance at both $f_{1}$ and $f_{2}$, respectively. The frequency span between $f_{2}$ and $f_{1}$ can be easily controlled, thereby reducing the required spectrum. Moreover, the proposed technique allows the storage of a large amount of data in a compact size to reduce the cost per bit. A multi-resonator prototype consisting of six resonators is designed, analyzed, and experimentally characterized. This prototype is implemented on the RT Duroid 5880 substrate with a dielectric constant of 2.2, loss tangent of 0.0009 , and thickness of $0.79 \mathrm{~mm}$. The designed configuration can be reconfigured for $4^{6}$ codes. Two complete the RFID tags, including the six resonators and two orthogonally polarized transmitting and receiving antennas, are implemented and tested. The first tag code is designed for all ones, 111111111111, and the second tag is designed as 101010101010 code. Experimental results show good agreement with the simulation.
\end{abstract}

Keywords: chipless RFID; retransmitted based; four-state resonator; ultra wide band (UWB) antenna; internet of things (IoT)

\section{Introduction}

In a radio frequency identification (RFID) system, radio frequency waves are used to read identification codes implemented on a tag. The main components of an RFID system include: An RFID transponder (a tag containing a sequence of electronic codes used for object identification), and an RFID reader (an interrogator that collects information from the tag) [1]. However, low-cost applications are still dominated by traditional barcodes rather than RFID tags, owing to the high prices of the latter [2]. Therefore, chipless RFID tags have recently attracted attention as a promising candidate to replace barcodes. The size and capacity of chipless RFID tags are among the main challenges for their cost reduction and thus wide adoption.

Different methods are reported in the literature for data encoding in chipless RFID tags. Generally, these encoding techniques can be classified into various domains, such as time, frequency, phase, and hybrid-domains [3]. In time-domain-based systems [4,5], the RFID reader interrogates the tag with a sequence of short pulses. Subsequently, the tag receives the interrogating pulses and then retransmits the response signal as a train of echoes with some time delays. The presence or absence of echoes and their position along the time axis are used to read out the tag ID. The surface acoustic wave (SAW) chipless RFID tag is the most popular and commercial time-domain-based chipless tag [6]. However, these tags are not recommended for cost-effective applications, owing to the high material costs and complex fabrication process. In frequency-based chipless RFID systems $[7,8]$, the reader interrogates the tag with an electromagnetic (EM) waveform and then the tag retransmits (or backscatters) the response to the RFID reader. In the phase domain, differences in the phase profile 
are used to encode the bits $[9,10]$. In hybrid-domain encoding techniques, more than one domain is used. These additional domains include phase-frequency [11,12], time-frequency [13], impedance loading [14], polarization-phase [15], and frequency-position [16]. However, as mentioned in [17], for a significant number of bits, hybrid-domain techniques still require a very high spectral bandwidth and the resultant configuration in this case will not be matched for low-cost readers.

Returning to frequency-domain chipless RFID systems, there are two different types of tags: Backscattering-based and retransmission-based. In the backscattering technique, the tag contains only resonating elements, where no separate antennas are required $[18,19]$. More advantages of this technique include the tag's small size and easier readability. However, adding more bits introduces coupling and affects the resonance frequency of the other units, and more calibration may be required to overcome this influence [20]. As shown in Figure 1, a retransmission-based chipless RFID tag consists of orthogonally polarized transmitting and receiving antennas and a sequence of $\mathrm{n}$ resonators (for an n-bit tag), in which the information is stored [1,21]. The presence or absence of a resonance is encoded as 1 (at which $\mathrm{S} 21<-10 \mathrm{~dB}$ ) or 0 , respectively. The resonators are always implemented with a microstrip structure; hence, its ground acts to minimize the effect of the object to which the tag is attached. In addition, this technique has a more stable performance because the use of two orthogonally polarized antennas significantly reduces the interference between the transmitted and received waves [20]. Moreover, the tag capacity can be increased by simply adding more resonators to the structure and the arising mutual coupling can be reduced by adjusting the distance between the resonators. Retransmission chipless RFID tags are based on stopband resonators. Stopband characteristics in the microstrip technique can be achieved by either directly connecting quarter-wave stubs to the feeder line [22-25], or by a short-circuited quarter-wave coupled line, as shown in Figure 2. The short circuit shown in Figure 2 can be replaced by another quarter-wave open-circuit stub to produce various forms of tags. Several chipless RFID tags have been developed based on these types of resonators, such as spiral resonators [26-30], open-loop resonators [31], L-strip shaped resonators [32], and complementary split-ring resonators (CSRR) [33]. An improved structure that combines a spiral and T-shaped coupled line in a compact form is proposed in [34]. Each resonator in these configurations is represented by only one bit; hence, an $n$-bit tag requires $n$ resonators and produces $2^{n}$ codes.

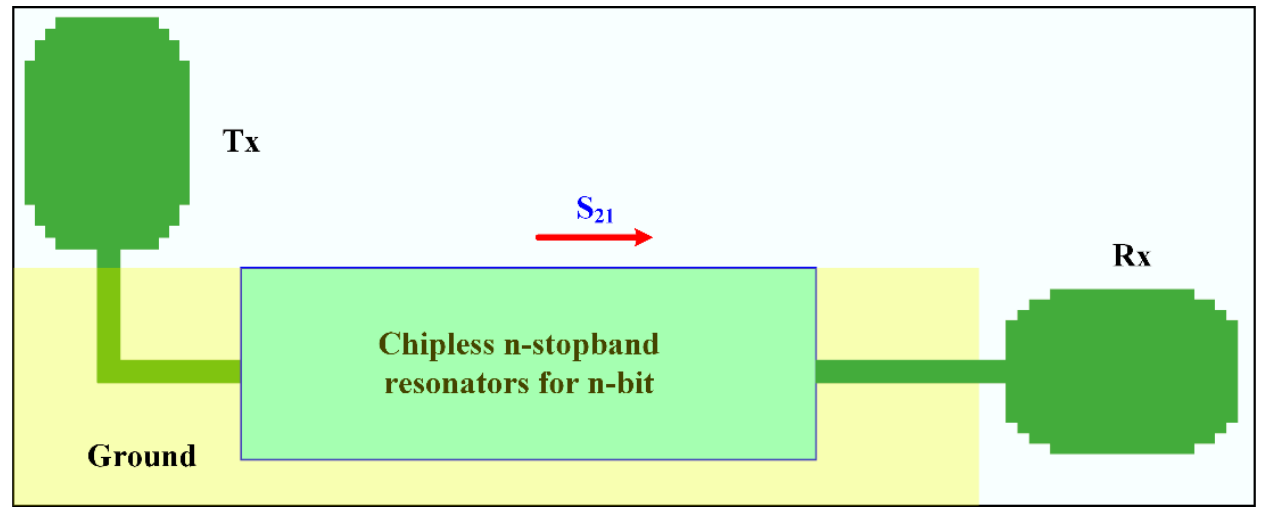

Figure 1. Simple block diagram of retransmission chipless radio frequency identification (RFID) tag.

In this paper, a new coupled-line microstrip resonator is proposed for compact high-capacity chipless RFID tags. Each resonator can store either 00 (no frequency response), 01 (resonance at $f_{2}$ ), 10 (resonance at $f_{1}$ ), or 11 (resonance at both $f_{1}$ and $f_{2}$ ). The frequency span between $f_{2}$ and $f_{1}$ can be easily controlled, thereby reducing the required spectrum. In other words, every resonator of the proposed tag can encode two bits. The proposed technique allows the storage of a large amount of data in a compact size to reduce the cost per bit. The prototype consisted of six microstrip resonators designed and fabricated on the RT Duroid 5880 substrate $\left(\varepsilon_{r}=2.2, \tan \sigma=0.0009\right.$, and $\left.h=0.79 \mathrm{~mm}\right)$. The information of each resonator can be stored in two frequencies $f_{1}$ and $f_{2}$. The implemented tag 
prototype can be reconfigured for $4^{6}$ codes and 12 possible frequencies. The prototype was fabricated and the results were validated. The measured results were found to be in good agreement with the simulations. The remainder of this paper is organized as follows. Section 2 discusses the basic operation of the proposed resonator. The analysis and design of the six resonators of the suggested structure are explained in Section 3. Three different codes are also designed and experimentally validated. The design and testing of a complete RFID tag based on the proposed structure are discussed in Section 4. Finally, conclusions are drawn in Section 5.

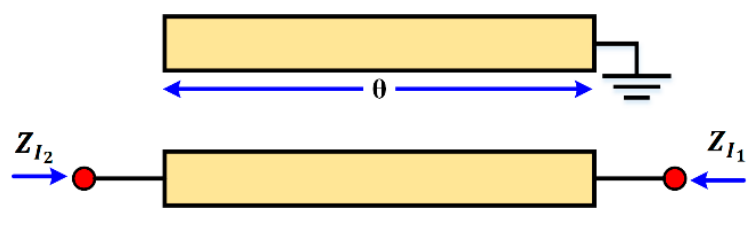

(a)

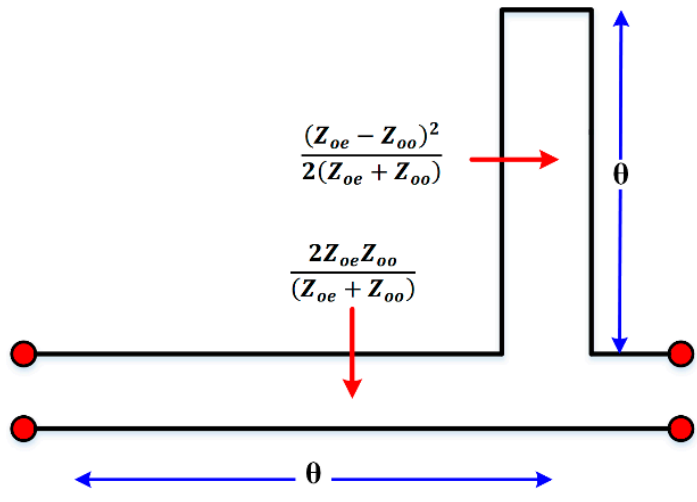

(b)

Figure 2. Coupled resonator (a) geometry and (b) equivalent circuit.

\section{Two-Bit Coupled-Line Stopband Resonator}

The schematic diagram and equivalent circuit of the proposed coupled-line resonator are shown in Figure 2. This coupled-line resonator can be analyzed in the manner suggested by Jones and Bolljahn [35]. The stopband characteristics of this resonator can be explained in terms of image impedances $Z_{I 1}$ and $Z_{I 2}$.

The image impedances of the coupled line shown in Figure 2 at ports 1 and 2 are given by the following:

$$
\begin{gathered}
Z_{I_{1}}=\frac{2 Z_{o e} Z_{o o} \cos \theta}{\sqrt{-\left(Z_{o e}-Z_{o o}\right)^{2}+\left(Z_{o e}+Z_{o o}\right)^{2} \cos ^{2} \theta}} \\
Z_{I_{2}}=\frac{Z_{o e} Z_{o o}}{Z_{I_{1}}}
\end{gathered}
$$

where $\theta$ is the coupled line electrical length, and $Z_{o e}$ and $Z_{o o}$ are the characteristic impedances of the even and odd mode, respectively. These equations show that the fundamental stopband resonance occurs when $\theta=\pi / 2$, that is, when the coupled line length is equal to one quarter-wavelength at the fundamental resonance frequency $f_{0}$. This structure also produces stopband characteristics at all odd harmonics.

For the purpose of compactness, or any other appropriate layout arrangements, the quarter-wavelength line can be bent (as shown in Figure 3) without losing the stopband behavior, apart from a slight shift in the resonance frequency. If the electrical length of the coupled line section is denoted as $\theta_{1}$ and the electrical length of the vertical line is $\theta_{2}$, then the total electric length is $\theta=\theta_{1}+\theta_{2}$. At the fundamental resonance frequency, very little decrease in the total electrical length is noticed. As an example, $\theta$ changes from $90^{\circ}$ to $85^{\circ}$ when $\theta_{1}$ decreases from $90^{\circ}$ to $30^{\circ}$. However, the bandwidth of the resonator decreases as $\theta_{1}$ decreases. 


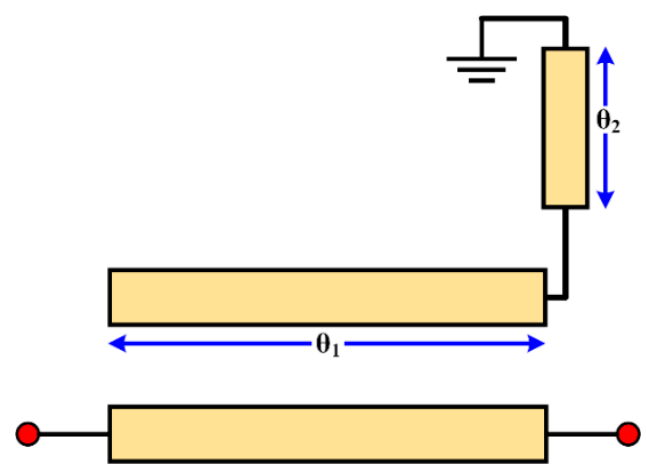

Figure 3. Coupled bent resonator.

For cost-effective chipless RFID, the short circuit is usually replaced by an open-circuit quarter-wavelength stub at $f_{0}$. In this case, the fundamental resonance frequency remains unchanged at $f_{0}$. However, the first harmonic appears at approximately $2 f_{0}$.

In our design, the short circuit in Figure 3 can be replaced by a quarter-wavelength open-circuit stub at $f_{1}$ or $f_{2}$, where $f_{1}$ and $f_{2}$ are close to each other. For a proof of concept, the proposed resonator shown in Figure 4 is designed to have $f_{1}$ and $f_{2}$ at 5 and $5.2 \mathrm{GHz}$, respectively. The circuit was designed on the Duroid substrate of a dielectric constant 2.2 and thickness $0.78 \mathrm{~mm}$. The physical parameters of the circuit shown in Figure 4 are given in Table 1 . This coupled line of length $l_{c}$ and width $w_{c}$ can be connected to arm 1 , arm 2 , or both arms using short metallic strips through a vertical arm of length $l_{v}$ and width $w_{v}$. This resonator can be reconfigured in order to present a quad-state.

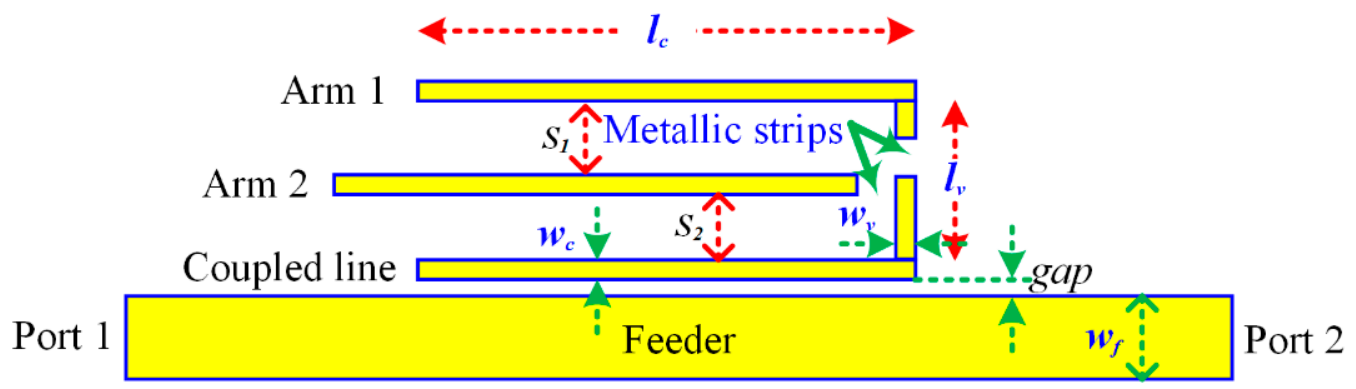

Figure 4. Geometry of the proposed resonator.

Table 1. Physical parameters of single coupled-line resonator.

\begin{tabular}{ccccccccc}
\hline Parameter & $w_{f}$ & $g a p$ & $l_{c}$ & $w_{c}$ & $l_{v}$ & $w_{v}$ & $S_{1}$ & $S_{2}$ \\
\hline Value $(\mathrm{mm})$ & 2.4 & 0.2 & 9.55 & 0.5 & 3.8 & 0.5 & 2 & 1.3 \\
\hline
\end{tabular}

The various types of states can be obtained using the connections shown in Figure 5. The first state, $S_{1}$-state, is achieved when arms 1 and 2 are not connected to the vertical line. No resonance can be observed in the band of operation, and this case is represented by the code 00 . If only arm 2 is connected to the vertical line by a short metallic strip, the resonator resonance frequency in this case is $f_{2}$ and the resonator is represented by the code 01 as shown in Figure $5 \mathrm{~b}\left(\mathrm{~S}_{2}\right.$-state). The third case, $\mathrm{S}_{3}$-state, is when only arm 1 is connected to the vertical line by a short metallic strip. The resonance frequency is $f_{1}$ and this state is represented by the code 10 . In the fourth sate, $\mathrm{S}_{4}$-state, both arms are connected to the vertical coupled line. Therefore, the resonance occurs at $f_{1}$ and $f_{2}$ and the resonator is represented by the code 11 . These four possible states are summarized in Table 2. 


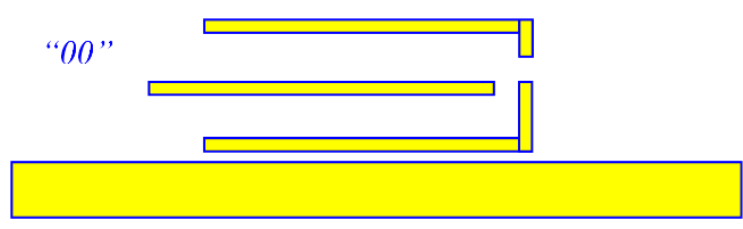

(a)

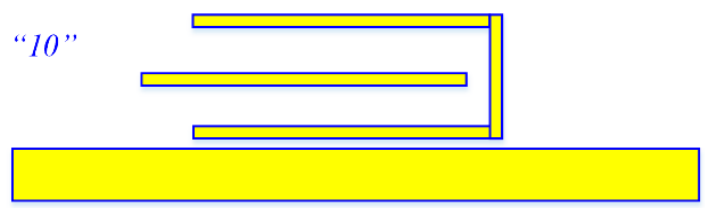

(c)

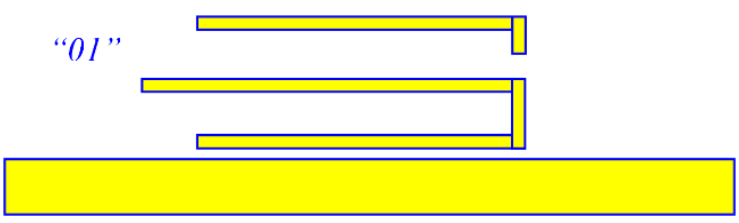

(b)

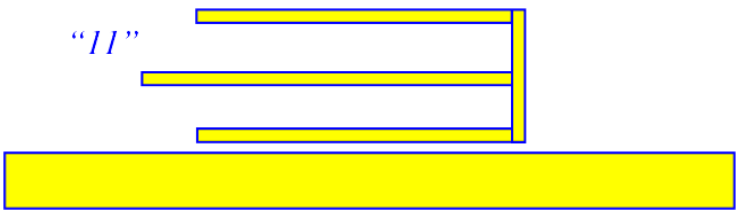

(d)

Figure 5. Four possible states for the single proposed resonator: (a) $S_{1}$ (no frequency), (b) $S_{2}\left(f_{2}\right.$ only), (c) $S_{3}\left(f_{1}\right.$ only), and (d) $S_{4}\left(f_{1}\right.$ and $\left.f_{2}\right)$.

Table 2. Possible states for single resonator.

\begin{tabular}{ccccc}
\hline Possible States & Arm 1 & Arm 2 & $f_{r}$ & Binary Code \\
\hline 1st state $\left(\mathrm{S}_{1}\right)$ & Not connected & Not connected & 0 & 00 \\
2nd state $\left(\mathrm{S}_{2}\right)$ & Not connected & Connected & $f_{2}$ & 01 \\
3rd state $\left(\mathrm{S}_{3}\right)$ & Connected & Not connected & $f_{1}$ & 10 \\
4th state $\left(\mathrm{S}_{4}\right)$ & Connected & Connected & $f_{1} f_{2}$ & 11 \\
\hline
\end{tabular}

Figure 6 shows the simulated insertion and return losses of a single quad-state microstrip resonator in four possible states "00," “01," “10," and "11." From this graph, there are two distinct resonant dip nulls in the magnitude of $S_{21}\left(f_{1}\right.$ and $\left.f_{2}\right)$. Additionally, there are two peaks in the magnitude of $\mathrm{S}_{11}$, which can be also used to identify the null location. The existence of a null in the insertion loss represents logic " 1 ," whereas the absence of the null represents logic " 0. "

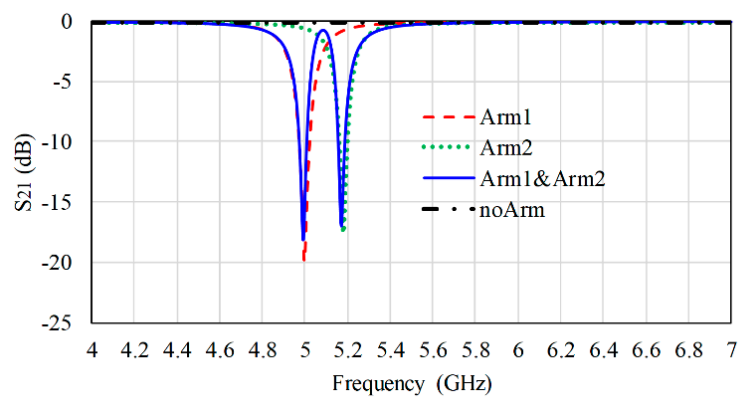

(a)

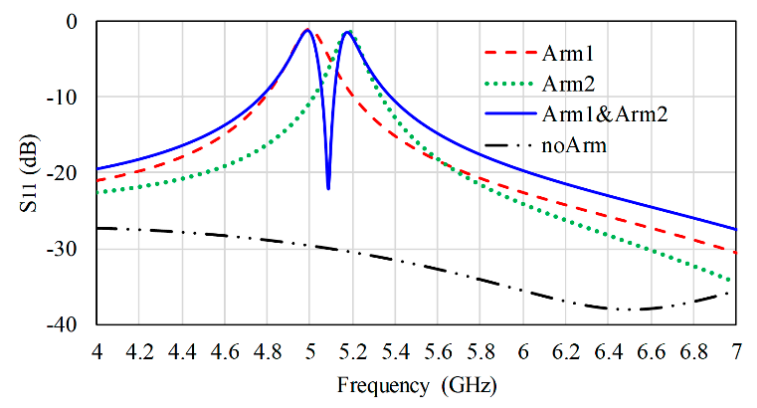

(b)

Figure 6. $S_{21}(a)$ and $S_{11}($ b) responses for the single quad-state microstrip resonator.

\section{Multi-Resonator Structure Design and Analysis}

A six-resonator circuit based on the proposed resonator discussed in the previous section was developed on the Duroid substrate of a dielectric constant 2.2 and thickness $0.78 \mathrm{~mm}$. The CST Microwave Studio was used to design and simulate the proposed tag. This structure was designed to maintain the frequency span for each resonator at approximately $200 \mathrm{MHz}$. The frequency span between each two adjacent resonators was also chosen to be approximately $200 \mathrm{MHz}$. The structure layout is shown in Figure 7. For the operation from 5.4 to $8 \mathrm{GHz}$, the resonator lengths were selected from $L_{1}=9.4 \mathrm{~mm}$ to $L_{6}=5.5 \mathrm{~mm}$. The separation between the adjacent resonators was $1 \mathrm{~mm}$. The feeder width was designed for a characteristic impedance of $50 \Omega$, which resulted in a width of $2.4 \mathrm{~mm}$ for the chosen substrate. The total length and width of the structure was 29.4 and $12.6 \mathrm{~mm}$, respectively. 


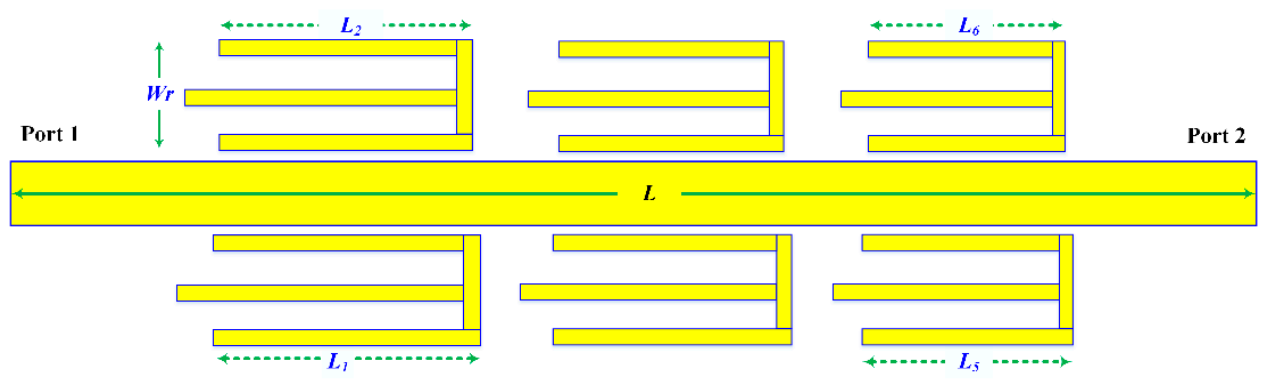

Figure 7. Six quad-state resonators.

Four configurations were developed to validate the concept. The first structure is shown in Figure 7, where all the resonators are connected to represent the code 11 for each one. Therefore, the configuration code is 111111111111 . The second configuration represents all zeros, where the two arms of all resonators are not connected. The third configuration represents code 101010101010, and obtained with arms 1 of all the resonators connected and arms 2 not connected. The fourth configuration represents 010101010101 , and consists of arms 2 of all the resonators connected and arms 1 not connected. The simulation results of $S_{21}$ and $S_{11}$ of the first two codes are shown in Figure 8. The simulation results of the first, third, and fourth codes are shown in Figure 9. It must be noted from this figure that almost no frequency shift was noticed when switching any resonator from one code to another. Many other codes, not presented in this paper, such as 011110011110, 110011001100, and 001100110011, were designed and verified.

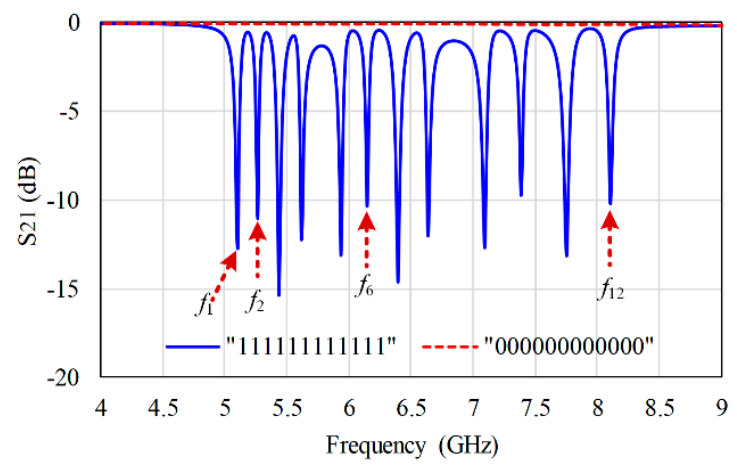

(a)

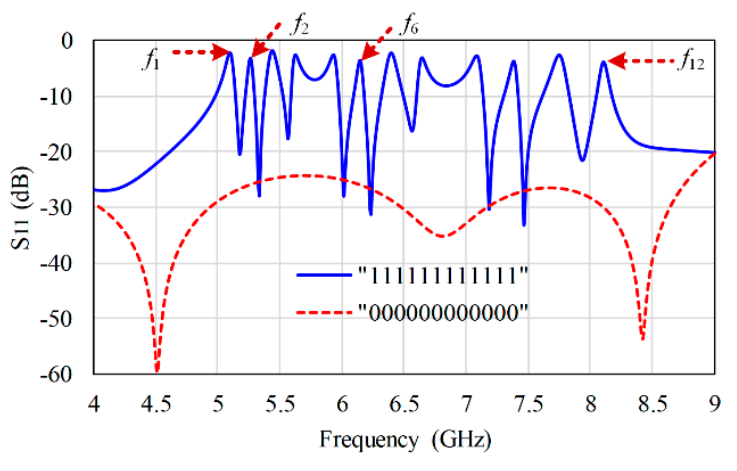

(b)

Figure 8. Simulated response of the proposed resonator tag with two different IDs: 111111111111 and 000000000000; (a) $S_{21}$ and (b) $S_{11}$.

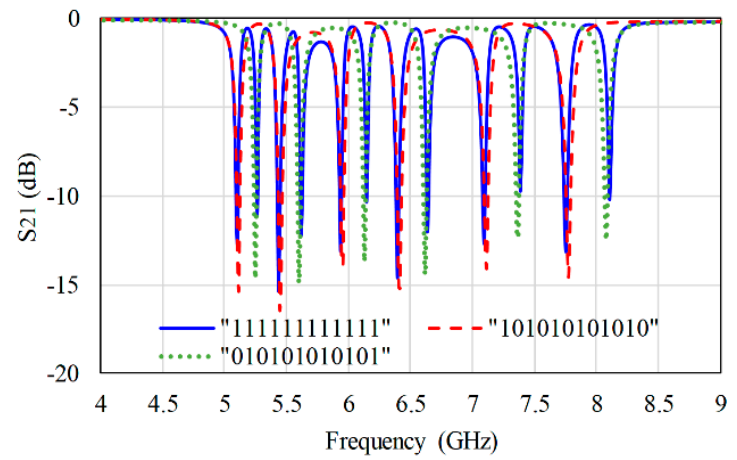

(a)

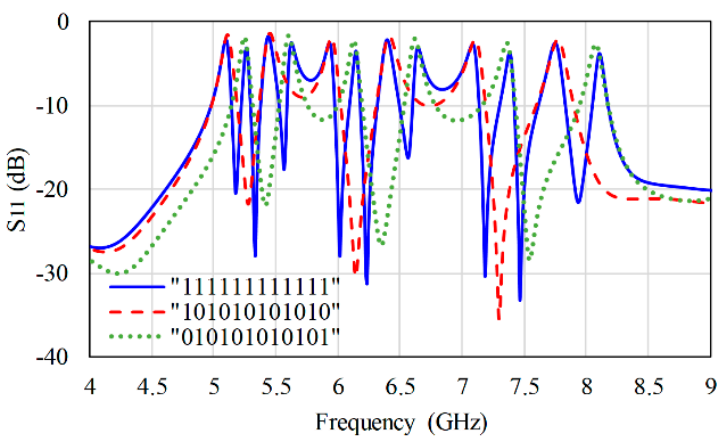

(b)

Figure 9. Simulated results of the proposed tag with three different codes: 111111111111, 101010101010, and $010101010101 ;$ (a) $S_{21}$ and (b) $S_{11}$. 
The three codes 111111111111, 101010101010, and 010101010101 were implemented and their photographs are shown in Figure 10. The measured and simulated $S_{21}$ were compared as shown in Figures 11-13. Only very small shifts to higher frequency were noticed in the measurements.

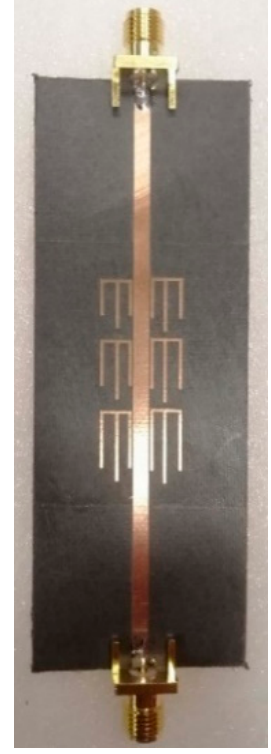

(a)

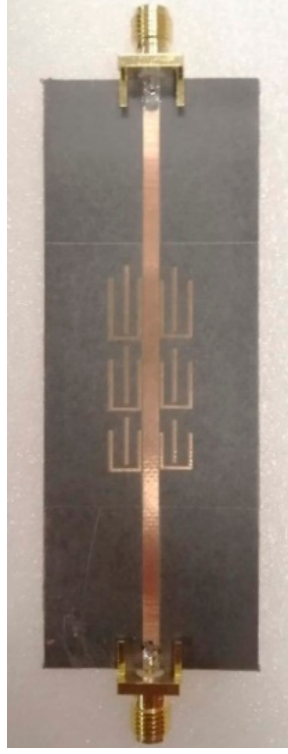

(b)

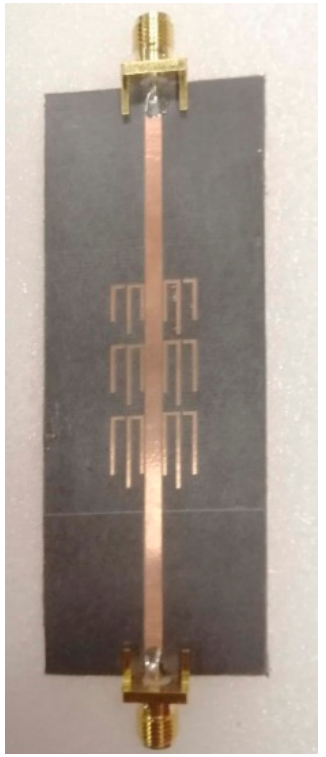

(c)

Figure 10. Fabricated codes: (a) 111111111111, (b) 101010101010, and (c) 010101010101.

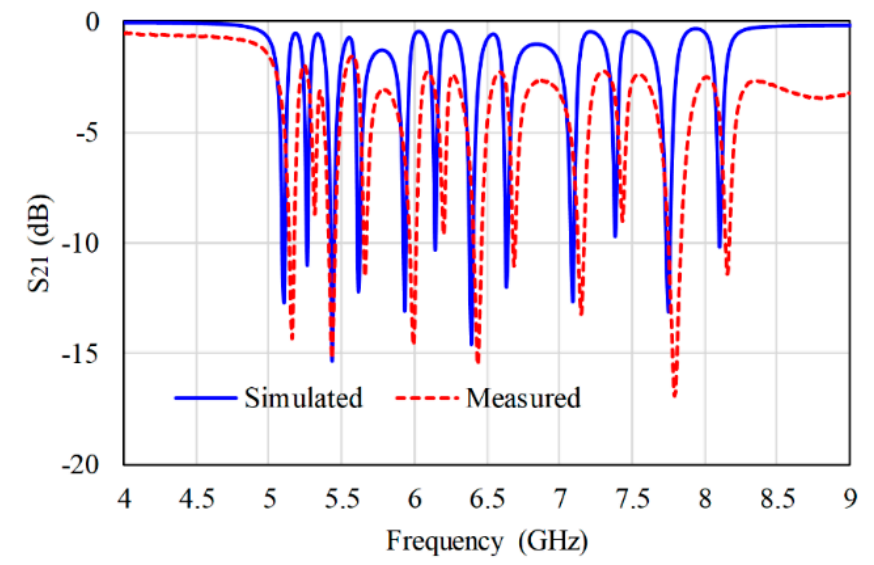

Figure 11. Measured and simulated $S_{21}$ for code (111111111111).

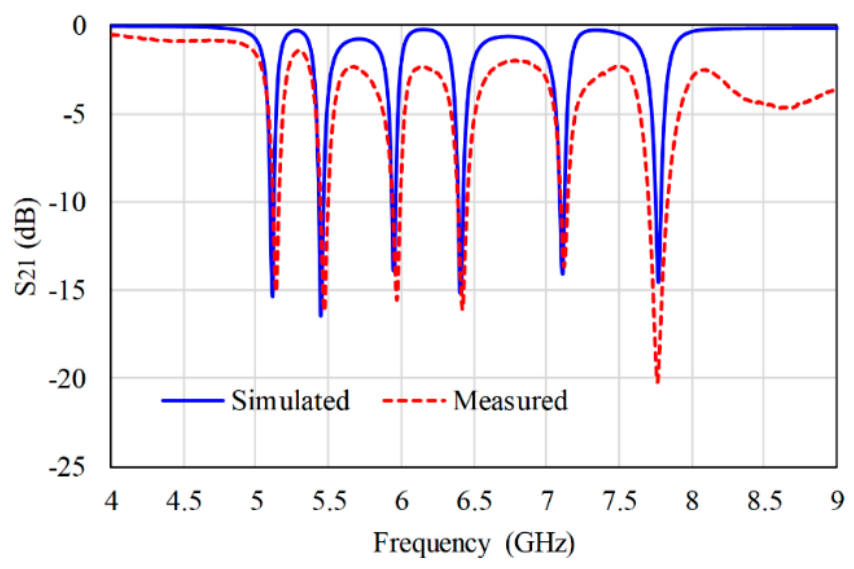

Figure 12. Measured and simulated $S_{21}$ for code 101010101010. 


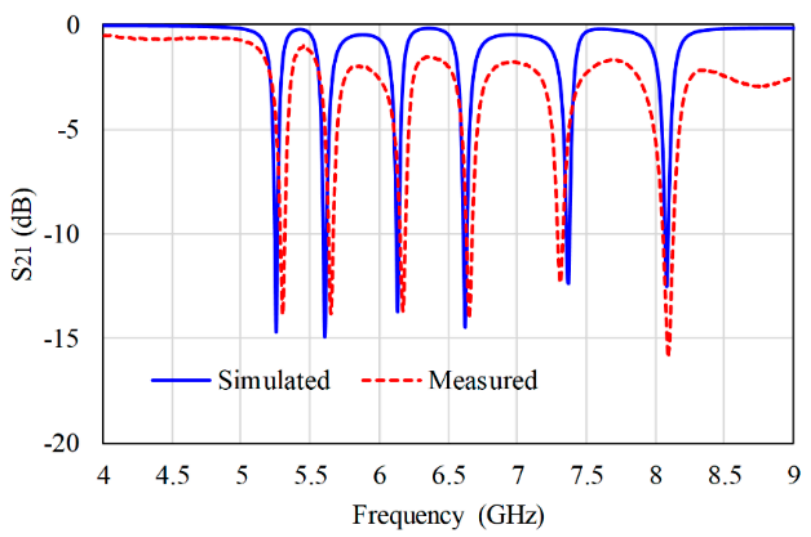

Figure 13. Measured and simulated $S_{21}$ for code 010101010101.

This may be attributed to the fabrication accuracy or high tolerance in the substrate parameters. The measurements were performed on an Anritsu Vector Network Analyzer (VNA 37369C), and showed good agreement with the simulations.

\section{Integrated Chipless RFID Tag Prototype}

Two typical wideband monopole antennas covering the frequency range from 5 to $10 \mathrm{GHz}$ were designed and optimized to verify the proposed tag experimentally. The antenna is shown in Figure 14, and its parameters are listed in Table 3. Figure 15a shows the simulated and measured return loss. The measured bandwidth for $\mathrm{S}_{11}<-10 \mathrm{~dB}$ was extended from $\mathrm{GHz}$ to $12 \mathrm{GHz}$. In addition, the 3D radiation pattern at $7 \mathrm{GHz}$ is displayed in Figure 15b.

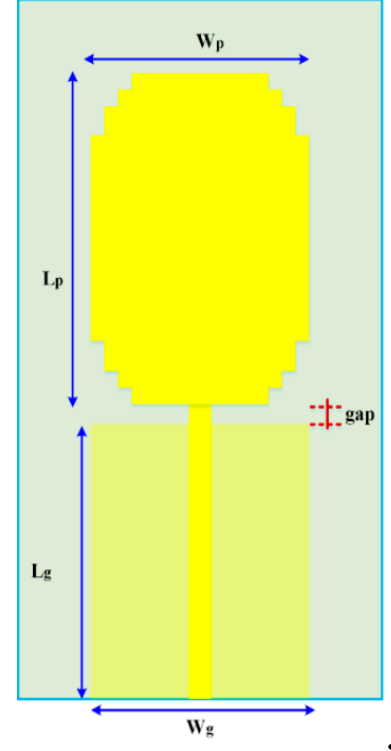

(a)

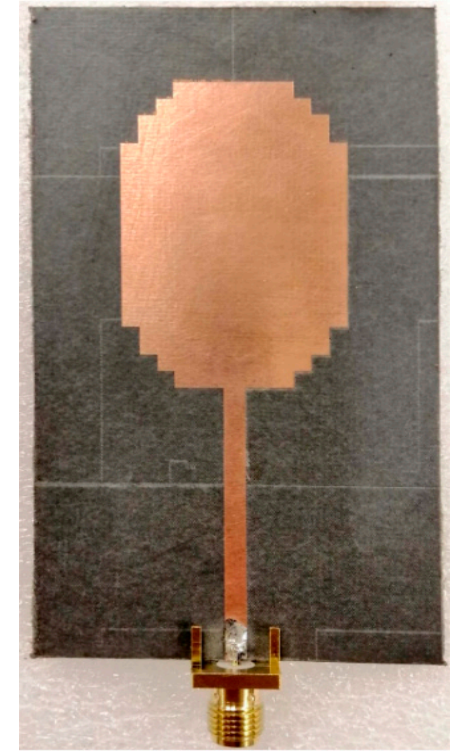

(b)

Figure 14. UWB antenna (a) geometry and (b) fabricated circuit.

Table 3. UWB antenna design parameters.

\begin{tabular}{cccc}
\hline Parameter & Value $(\mathbf{m m})$ & Parameter & Value $(\mathbf{m m})$ \\
\hline Patch length $\left(\mathrm{L}_{\mathrm{p}}\right)$ & 39.6 & Ground length $\left(\mathrm{Lg}_{\mathrm{g}}\right)$ & 34.5 \\
Patch width $\left(\mathrm{W}_{\mathrm{p}}\right)$ & 25 & Ground width $\left(\mathrm{W}_{\mathrm{g}}\right)$ & 25 \\
Gap between the patch & \multirow{2}{*}{0.52} & Feeder length $\left(\mathrm{L}_{\mathrm{f}}\right)$ & 35 \\
and ground plane $(\mathrm{gap})$ & & Feeder width $\left(\mathrm{W}_{\mathrm{f}}\right)$ & 2.4 \\
\hline
\end{tabular}




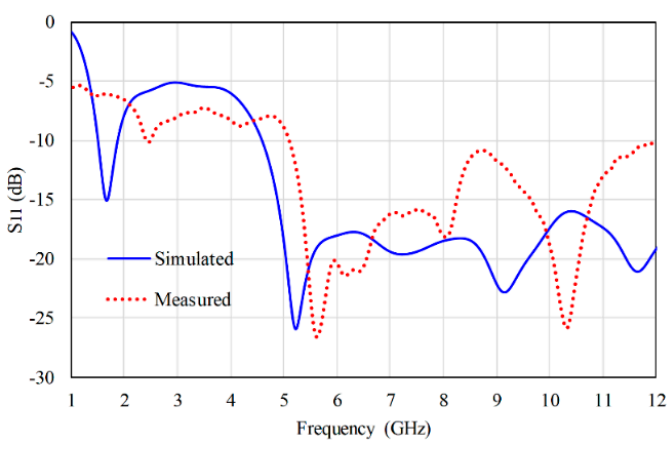

(a)

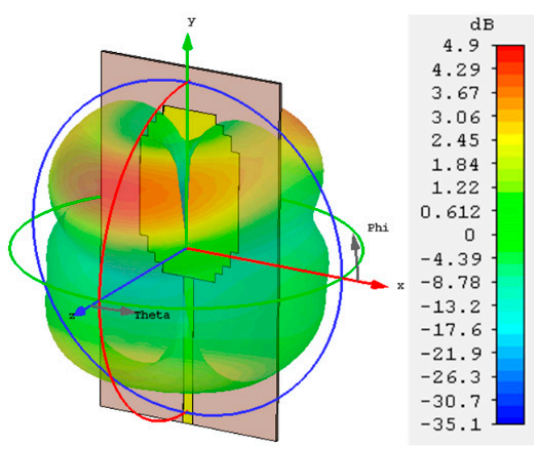

(b)

Figure 15. UWB antenna results (a) simulated and measured $S_{11}(\mathbf{b})$ simulated $3 D$ radiation pattern.

The two antennas were connected to opposite ends of the feeder line of the six-resonator structures implemented in the previous section. The two antennas were placed in an orthogonal-polarization arrangement, as shown in Figure 16.

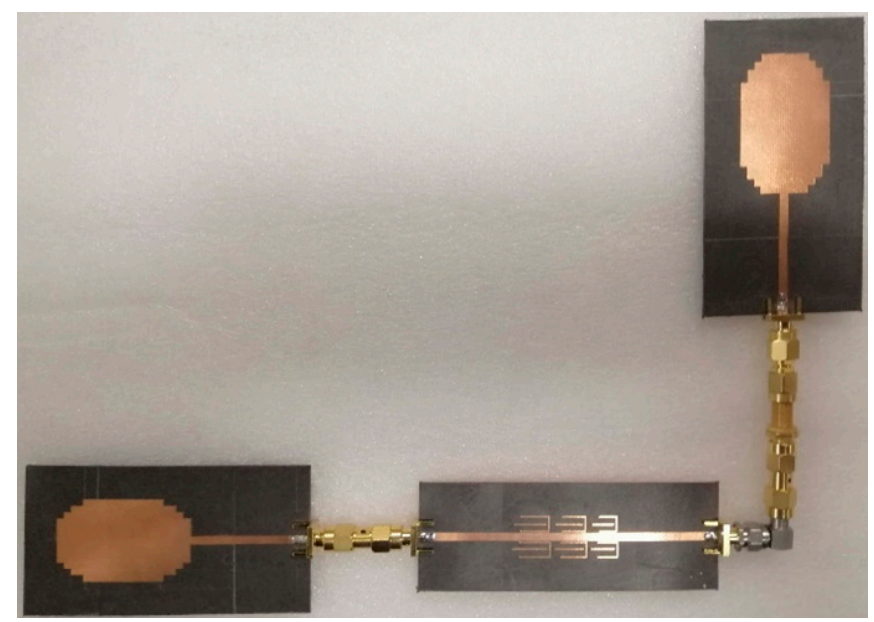

Figure 16. Integrated chipless RFID tag prototype.

A measurement setup was established to validate the proposed chipless RFID tag system, as shown in Figure 17. The test was performed in an anechoic chamber, and two different six-resonator tag codes were used. Tag (1) had code 111111111111, and tag (2) was 101010101010. The measured results of tag (1) and tag (2) are illustrated in Figures 18 and 19, respectively. It can be seen from these figures that the measured and simulated results matched well, with slight shifts in certain resonance frequencies.

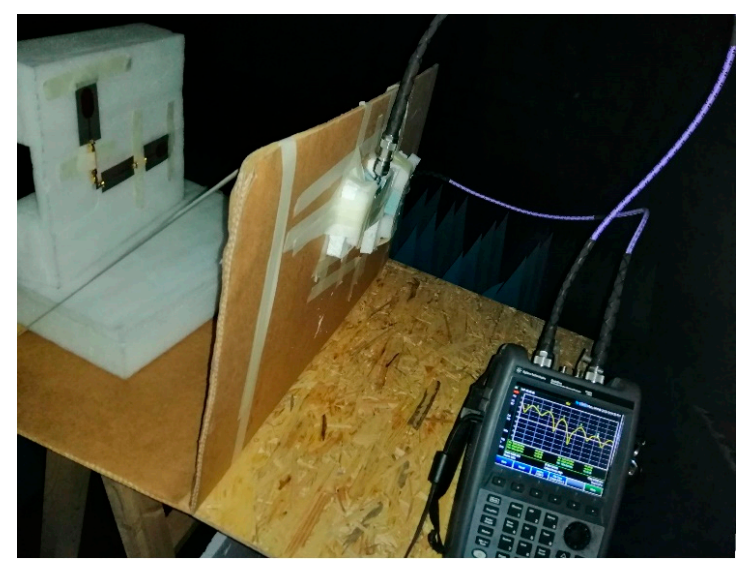

Figure 17. Measurement setup. 


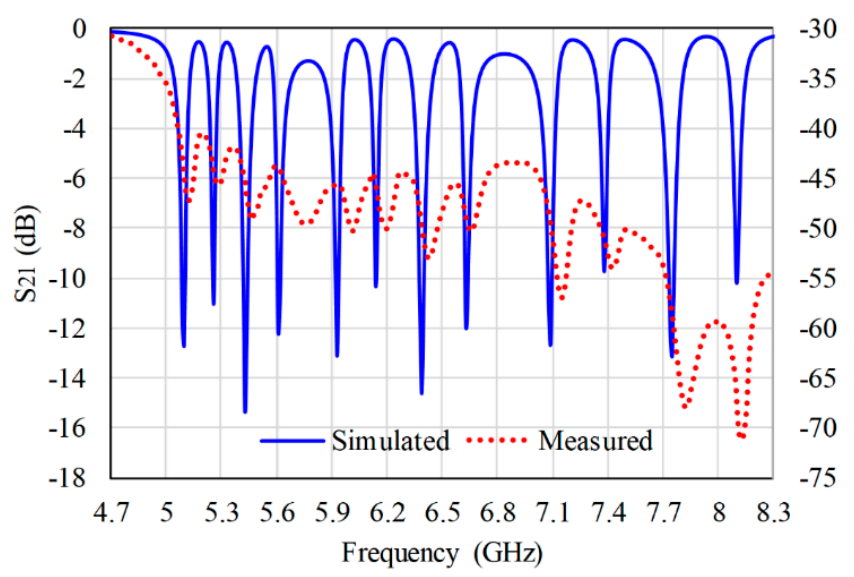

Figure 18. Measured and simulated $S_{21}$ of code 111111111111.

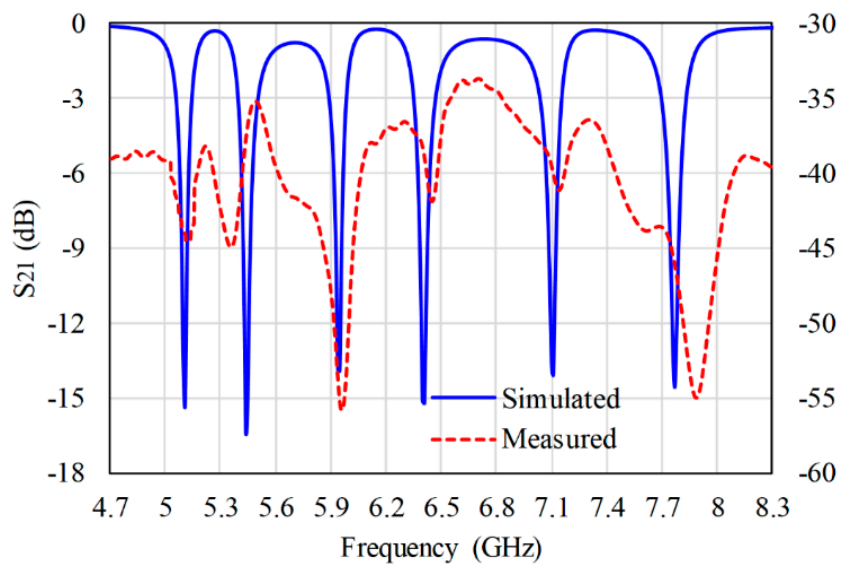

Figure 19. Measured and simulated $S_{21}$ of code 101010101010.

\section{Conclusions}

In this study, a novel and compact chipless RFID tag was designed and fabricated. This structure contains six quad-state microstrip coupled-line resonators. For each resonator, two resonance frequencies are possible; therefore, a single resonator can be reconfigured for two-bit information codes $(00,01,10$, and 11), which is more economical than conventional chipless RFID tag designs. The proposed tag can be reconfigured for $4^{6}$ codes and 12 possible frequencies. The measured insertion loss is found to be in good agreement with the simulation.

Author Contributions: Conceptualization, W.M.A. and A.-F.A.S.; Methodology, W.M.A. and A.-F.A.S.; Software, W.M.A.; Validation, W.M.A. and A.-F.A.S.; Formal Analysis, W.M.A. and A.-F.A.S.; Investigation, A.-F.A.S.; Resources, A.-F.A.S.; Data Curation, W.M.A.; Writing-Original Draft Preparation, W.M.A.; Writing-Review and Editing, W.M.A. and A.-F.A.S.; Visualization, W.M.A. and A.-F.A.S.; Supervision, A.-F.A.S.

Funding: This research received no external funding.

Acknowledgments: The authors would like to thank Deanship of scientific research for funding and supporting this research through the initiative of DSR Graduate Students Research Support (GSR).

Conflicts of Interest: The authors declare no conflict of interest.

\section{References}

1. Preradovic, S.; Karmakar, N.C. Chipless RFID: Bar code of the future. IEEE Microw. Mag. 2010, 11, 87-97.

2. Islam, M.A.; Yap, Y.; Karmakar, N. ' $\Delta$ ' slotted compact printable orientation insensitive chipless RFID tag for long range applications. In Proceedings of the 2016 9th International Conference on Electrical and Computer Engineering (ICECE), Dhaka, Bangladesh, 20-22 December 2016; pp. 283-286. 
3. Islam, M.; Yap, Y.; Karmakar, N.; Azad, A.K.M. Orientation independent compact chipless RFID tag. In Proceedings of the 2012 IEEE International Conference on RFID-Technologies and Applications (RFID-TA), Côte D'Azur, French, 5-7 November 2012; pp. 137-141.

4. Pöpperl, M.; Parr, A.; Mandel, C.; Jakoby, R.; Vossiek, M. Potential and practical limits of time-domain reflectometry chipless rfid. IEEE Trans. Microw. Theory 2016, 64, 2968-2976. [CrossRef]

5. Genovesi, S.; Costa, F.; Monorchio, A.; Manara, G. Chipless RFID Tag Exploiting Multifrequency Delta-Phase Quantization Encoding. IEEE Antennas Wirel. Propag. Lett. 2016, 15, 1. [CrossRef]

6. Plessky, V.P.; Reindl, L.M. Review on SAW RFID tags. IEEE Trans. Ultrason. Ferr. 2010, 57, 654-668. [CrossRef] [PubMed]

7. Herrojo, C.; Mata-Contreras, J.; Núñez, A.; Paredes, F.; Ramon, E.; Martín, F. Near-Field Chipless-RFID System With High Data Capacity for Security and Authentication Applications. IEEE Trans. Microw. Theory 2017, 65, 5298-5308. [CrossRef]

8. Islam, M.A.; Karmakar, N.C. Real-world implementation challenges of a novel dual-polarized compact printable chipless RFID tag. IEEE Trans. Microw. Theory. 2015, 63, 4581-4591. [CrossRef]

9. Barbot, N.; Perret, E. A Chipless RFID Method of 2D Localization Based on Phase Acquisition. J. Sens. 2018, 2018, 1-6. [CrossRef]

10. Balbin, I.; Karmakar, N.C. Phase-encoded chipless RFID transponder for large-scale low-cost applications. IEEE Microw. Wirel. Compon. Lett. 2009, 19, 509-511. [CrossRef]

11. Vena, A.; Perret, E.; Tedjini, S. Chipless RFID tag using hybrid coding technique. IEEE Trans. Microw. Theory 2011, 59, 3356-3364. [CrossRef]

12. Babaeian, F.; Karmakar, N.C. Hybrid Chipless RFID Tags- A Pathway to EPC Global Standard. IEEE Access 2018, 6, 67415-67426. [CrossRef]

13. Jimenez-Saez, A.; Schusler, M.; Nickel, M.; Jakoby, R. Hybrid time-frequency modulation scheme for chipless wireless identification and sensing. IEEE Sens. J. 2018, 18, 7850-7859. [CrossRef]

14. Ni, Y.Z.; Huang, X.D.; Lv, Y.P.; Cheng, C.H. Hybrid coding chipless tag based on impedance loading. IET Microw. Antennas Propag. 2017, 11, 1325-1331. [CrossRef]

15. Karmaker, N.C. Tag, you're it radar cross section of chipless RFID tags. IEEE Microw. Mag. 2016, 17, 64-74. [CrossRef]

16. Arjomandi, L.M.; Khadka, G.; Xiong, Z.; Karmakar, N.C.; Zixang, X. Document Verification: A Cloud-Based Computing Pattern Recognition Approach to Chipless RFID. IEEE Access 2018, 6, 78007-78015. [CrossRef]

17. Herrojo, C.; Mata-Contreras, J.; Paredes, F.; Núñez, A.; Ramon, E.; Martín, F. Near-field chipless-RFID system with erasable/programmable 40-bit tags inkjet printed on paper substrates. IEEE Microw. Wirel. Compon. Lett. 2018, 28, 272-274. [CrossRef]

18. Marindra, A.M.J.; Tian, G.Y. Chipless RFID Sensor Tag for Metal Crack Detection and Characterization. IEEE Trans. Microw. Theory 2018, 66, 2452-2462. [CrossRef]

19. Bibile, M.A.; Karmakar, N.C. Moving Chipless RFID Tag Detection Using Adaptive Wavelet-Based Detection Algorithm. IEEE Trans. Antenn. Propag. 2018, 66, 2752-2760. [CrossRef]

20. Zhang, Y.J.; Gao, R.X.; He, Y.; Tong, M.S. Effective Design of Microstrip-Line Chipless RFID Tags Based on Filter Theory. IEEE Trans. Antenn. Propag. 2019, 67, 1428-1436. [CrossRef]

21. Adbulkawi, W.M.; Sheta, A.A. A Compact Chipless RFID Tag Based on Frequency Signature. In Proceedings of the 2017 9th IEEE-GCC Conference and Exhibition (GCCCE), Manama, Bahrain, 8-11 May 2017; pp. 1-4.

22. Ashraf, M.A.; Alshoudokhi, Y.A.; Behairy, H.M.; Alshareef, M.R.; Alshebeili, S.A.; Issa, K.; Fathallah, H. Design and Analysis of Multi-Resonators Loaded Broadband Antipodal Tapered Slot Antenna for Chipless RFID Applications. IEEE Access 2017, 5, 25798-25807. [CrossRef]

23. Nijas, C.M.; Dinesh, R.; Deepak, U.; Rasheed, A.; Mridula, S.; Vasudevan, K.; Mohanan, P. Chipless RFID tag using multiple microstrip open stub resonators. IEEE Trans. Antenn. Propag. 2012, 60, 4429-4432. [CrossRef]

24. Jalil, M.E.; Rahim, M.K.A.; Samsuri, N.A.; Dewan, R. Chipless RFID tag based on meandered line resonator. In Proceedings of the 2014 IEEE Asia-Pacific Conference on Applied Electromagnetics (APACE), Johor Bahru, Malaysia, 8-10 December 2014; pp. 203-206.

25. Khaliel, M.; El-Hadidy, M.; Kaiser, T. Printable depolarizing chipless RFID tag based on DGS resonators for suppressing the clutter effects. In Proceedings of the 2015 9th European Conference on Antennas and Propagation (EuCAP), Lisbon, Portugal, 12-17 April 2015; pp. 1-5. 
26. Preradovic, S.; Balbin, I.; Karmakar, N.C.; Swiegers, G.F. Multiresonator-based chipless RFID system for low-cost item tracking. IEEE Trans. Microw. Theory 2009, 57, 1411-1419. [CrossRef]

27. Preradovic, S.; Karmakar, N.C. Design of fully printable planar chipless RFID transponder with 35-bit data capacity. In Proceedings of the 2009 European Microwave Conference (EuMC), Rome, Italy, 1 October 2009; pp. 013-016.

28. Preradovic, S.; Karmakar, N.C. Design of Chipless RFID Tag for Operation on Flexible Laminates. IEEE Antennas Wirel. Propag. Lett. 2010, 9, 207-210.

29. Alves, A.A.C.; Spadoti, D.H.; Bravo-Roger, L.L. Optically Controlled Multiresonator for Passive Chipless Tag. IEEE Microw. Wirel. Compon. Lett. 2018, 28, 467-469. [CrossRef]

30. Abdulkawi, W.M.; Sheta, A.A. Printable Chipless RFID Tags for IoT Applications. In Proceedings of the 2018 1st International Conference on Computer Applications \& Information Security (ICCAIS), Riyadh, Saudi Arabia, 4-6 April 2018; pp. 1-4.

31. Sharma, V.; Hashmi, M. Chipless RFID tag based on open-loop resonator. In Proceedings of the 2017 IEEE Asia Pacific Microwave Conference (APMC), Kuala Lumpur, Malaysia, 13-16 November 2017; pp. 543-546.

32. Ma, Z; Chen, C.C. A hybrid coding retransmitted chipless tag loaded by microstrip resonator. Microelectron. Reliab. 2019, 93, 1-7. [CrossRef]

33. Ma, Z.H.; Yang, J.H.; Chen, C.C.; Yang, C.F. A re-transmitted chipless tag using CSRR coupled structure. Microsyst. Technol. 2018, 24, 4373-4382. [CrossRef]

34. Abdulkawi, W.M.; Sheta, A.F.A. Multi-Resonator Structure for Small Size Chipless Radio Frequency Identification Tag. Int. J. Comput. Digit. Syst. 2018, 7, 43-49. [CrossRef]

35. Jones, E. Coupled-Strip-Transmission-Line Filters and Directional Couplers. IRE Trans. Microw. Theory Tech. 1956, 4, 75-81. [CrossRef]

(C) 2019 by the authors. Licensee MDPI, Basel, Switzerland. This article is an open access article distributed under the terms and conditions of the Creative Commons Attribution (CC BY) license (http://creativecommons.org/licenses/by/4.0/). 